\title{
Intramedullary Subependymoma of the Cervical Spinal Cord: A Case Report and Review of the Literature
}

\author{
Eiralí Guadalupe García Chapa ${ }^{1}$ Juana Elizabeth Tadeo González ${ }^{1}$ Mauricio Delgado Morquecho ${ }^{1}$ \\ José Armando Díaz Martínez ${ }^{2}$ Mariana Mercado Flores ${ }^{3}$ Ángel Martínez Ponce De León² \\ Oralia Barboza Quintana ${ }^{1}$ Rodolfo Franco Márquez ${ }^{1}$
}

${ }^{1}$ Anatomic Pathology and Cytopathology Service, Universitary Hospital of Autonomous University of Nuevo León, Monterrey, Mexico

${ }^{2}$ Neurosurgery and Neurological Endovascular Therapy Service, Universitary Hospital of Autonomous University of Nuevo León, Monterrey, Mexico

${ }^{3}$ Department of Radiology, Universitary Hospital of Autonomous University of Nuevo León, Monterrey, Mexico

\begin{abstract}
Address for correspondence Eiralí Guadalupe García Chapa, MD, Anatomic Pathology and Cytopathology Service, Universitary Hospital of Autonomous University of Nuevo León, Universidad Autonoma de Nuevo León, Facultad de Medicina, Avenida Francisco I. Madero S/N, Mitras Centro, 64460 Monterrey, NL, Mexico (e-mail: eiraly_g@hotmail.com).
\end{abstract}

Indian J Neurosurg 2019;8:64-68

\begin{abstract}
Keywords

- subependymoma

- cervical spinal cord

- glial fibrillary acidic protein

Subependymoma is a rare tumor of the central nervous system, representing 0.2 to $0.7 \%$ of all intracranial tumors. They are usually found in the fourth ventricle or in the walls of the lateral ventricles, often remaining asymptomatic. Subependymomas occur rarely in the cervical or thoracic spinal cord. Since its first description in the spinal cord by Boykin et al in 1954, only 47 cases have been reported. A 49-year-old man presented with a 4-year-long-lasting neck pain, which radiated to the upper right extremity for 4 years. It was insidious at onset and revealed gradual progression, difficulty in performing fine hand movements, and hyperalgesia. Magnetic resonance imaging revealed irregular hyperintensity of $\mathrm{T} 2$ and dilatation of the spinal cord from C4 to T1 with associated edema and an intramedullary lesion with central location. During the surgical event, a transoperative biopsy was performed that revealed loose fibrillary networks and groups of nuclei showing mild pleomorphism and microcystic formations. Histologically, we observed groups of cells with mild nuclear pleomorphism embedded in a dense, thin, glial fibrillar fundus, and microcystic formations. Immunohistochemical staining revealed diffuse positivity for the glial fibrillary acidic protein, and negative for the epithelial membrane antigen. Subependymoma accounts for $8.3 \%$ of all ependymal tumors. There are few descriptions of the cytologic features of the subependymoma because this neoplasm is rare and most commonly found incidentally in autopsies.
\end{abstract}

\section{Introduction}

Subependymoma is a rare central nervous system (CNS) tumor, first described by Scheinker in 1945, accounting for 0.2 to $0.7 \%$ of all intracranial tumors. These are usually found in the fourth ventricle or on the lateral ventricle walls, often remaining asymptomatic with an incidental frequency of 0.13 to $0.4 \%$ in autopsy cases. ${ }^{1}$ Subependymomas rarely occur in the cervical or thoracic spinal cord, and when they occur, they are inevitably accompanied by myelopathy and are often diagnosed clinically as ependymomas or astrocytomas. ${ }^{1}$ The location of these lesions in the spinal cord suggests a subpial glial progenitor origin rather than its proposed origin from subependymal progenitor cells. ${ }^{2}$ Since its first description in the spinal cord by Boykin et al in 1945 , only 47 cases have been reported to date. ${ }^{3}$ received

July 28, 2017

accepted

March 16, 2018

published online

March 27, 2019
C2019 Neurological Surgeons'

Society of India
License terms

() (1) $\ominus \circledast$ 


\section{Case Report}

A 49-year-old man presented with a burning neck pain, which irradiated to the lateral side of right upper extremity for 4 years. It was insidious at onset and revealed gradual progression, difficulty in performing fine hand movements, and hyperalgesia.

The patient had hyperalgesia in dermatomes $\mathrm{C} 5$ and $\mathrm{T} 6$ and a grade $3 / 5$ power in his right upper limb with muscle wasting. Rest of his limbs had mild weakness with spasticity and hyperreflexia. Sagittal T2 magnetic resonance imaging (MRI) revealed irregular hyperintensity and widening of the spinal cord from C4 to T1 with associated edema; an intramedullary lesion with central location; and an intense, heterogeneous, and patchy enhancement after gadolinium administration (-Fig. 1).

\section{Surgical Procedure}

Laminoplasty of C3-C4-C5 was performed. After opening the dura mater, the tumor was identified totally covered

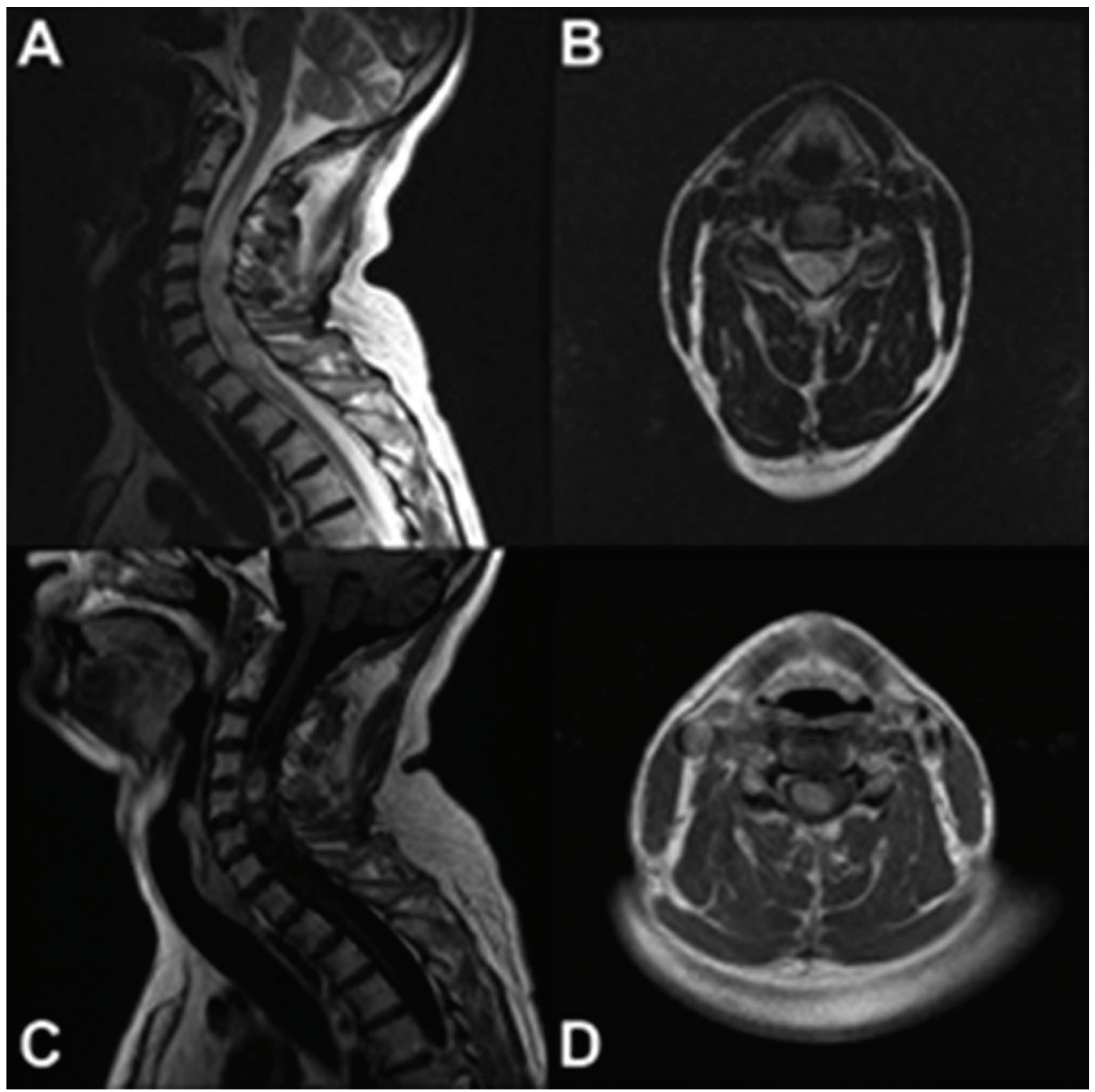

Fig. 1 (A) Sagittal T2, hyperintensity and widening of spinal cord from C4-T1. (B) Axial T2 shows intramedullary lesion. (C) Sagittal T1 with gadolinium patchy enhancement. (D) Axial T1 with gadolinium, intense enhancement of the lesion. 
demarcated, and located in the right lateral portion of the spinal cord near $\mathrm{C} 4$, followed by a near-total surgical resection (-Fig. 2 ).

\section{Histologic Examination}

Cytologic examination during surgery revealed that the mass was composed of loose fibrillary networks and clusters of nuclei showing mild pleomorphism. Several microcystic formations were evident. On frozen section, we observed clusters of cells with mild nuclear pleomorphism embedded in a dense, fine, glial fibrillary background, and microcystic formations. Histologically, the neoplasm was considered benign.
All of the resected tissue was submitted for histopathologic analysis, processed and embedded in paraffin blocks. On histopathologic examination, the same findings described before were observed (-Fig. 3). Immunohistochemistry staining revealed diffuse positivity for glial fibrillary acidic protein (GFAP), but tumor cells were negative to epithelial membrane antigen (EMA) (-Fig. 4).

\section{Discussion}

Subependymoma is a rare, benign, slow-growing CNS tumor and accounts for $8.3 \%$ of all ependymal tumors. ${ }^{1-3}$ So far, 32 cases have been located in the cervical, cervicomedullary, and cervicothoracic locations. ${ }^{2}$ They have a mean age

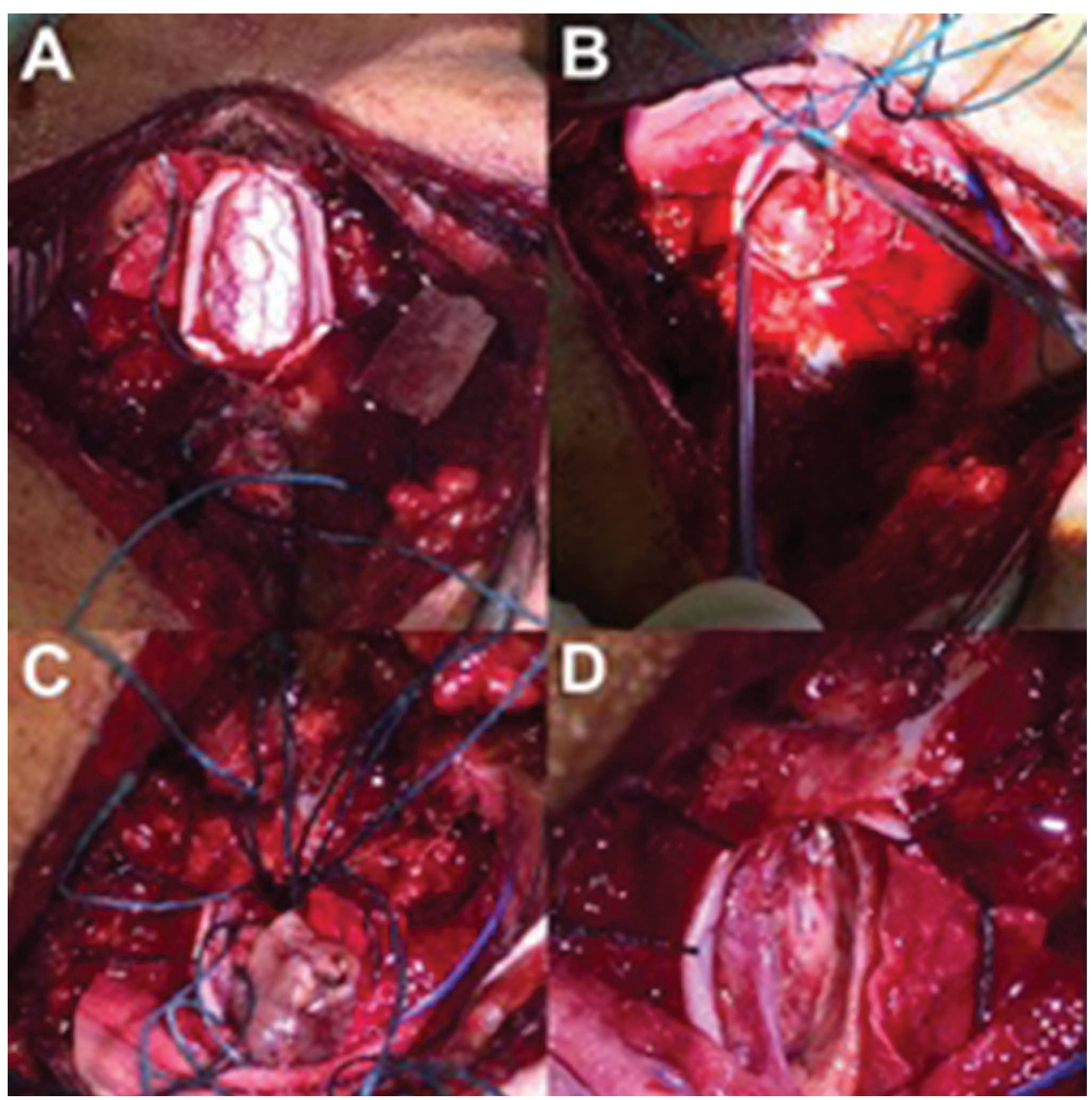

Fig. 2 Surgical findings. (A) Longitudinal section a plum beneath the pia can be observed. (B) Longitudinal section of pia: a white-red tumor can be observed. (C) Resection of tumor with a nodular, jelly appearance can be observed. (D) spinal cord without the tumor. 


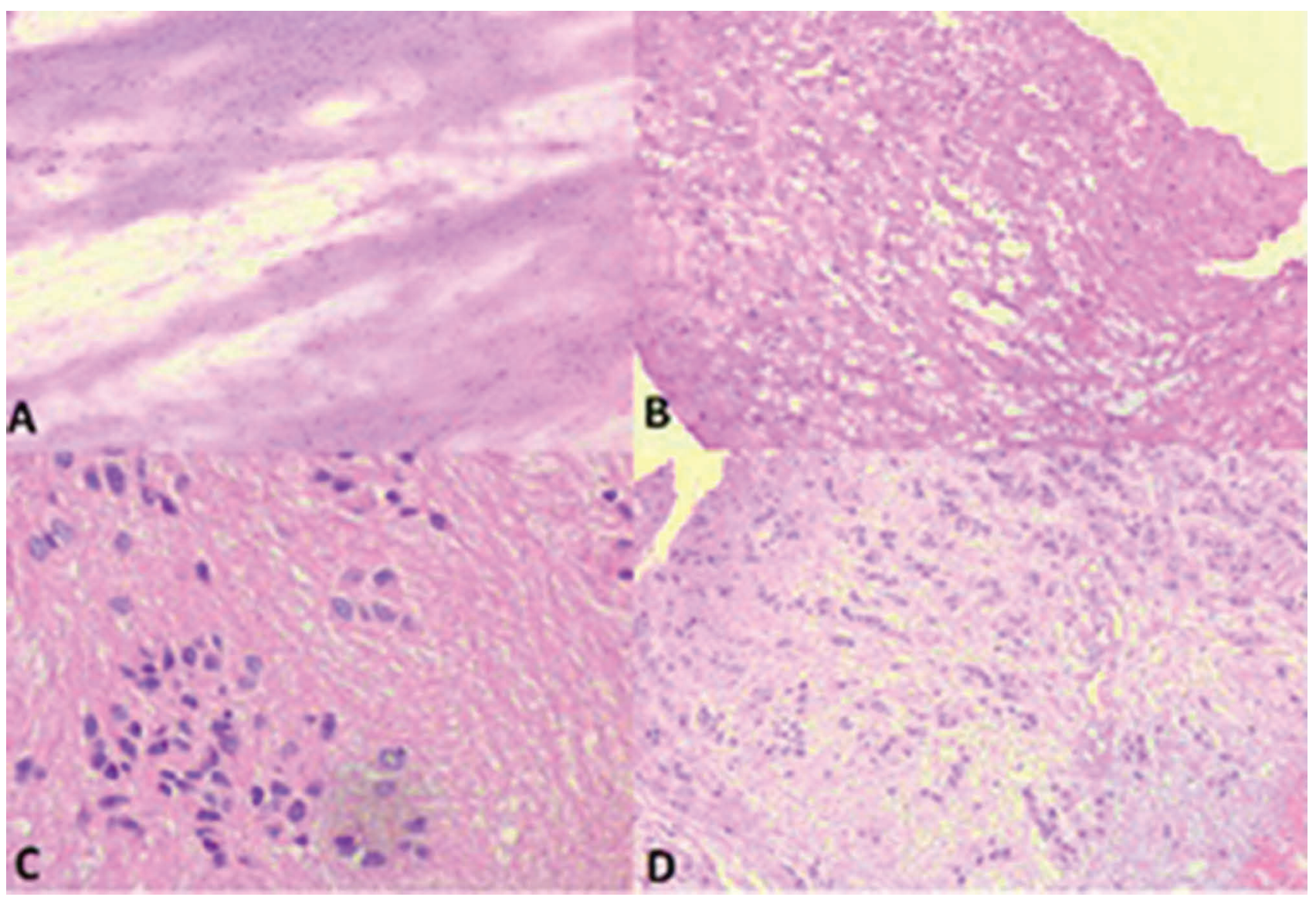

Fig. 3 Histopathology: (A) H\&E staining smear shows loose fibrillary networks and clusters of nuclei showing mild pleomorphism, (B) H\&Estained frozen section shows lobular pattern arrangement of monomorphic nuclei in fibrillary pattern. (C, D) H\&E staining shows clusters of cells with mild nuclear pleomorphism embedded in a dense, fine, glial fibrillary background and microcystics.

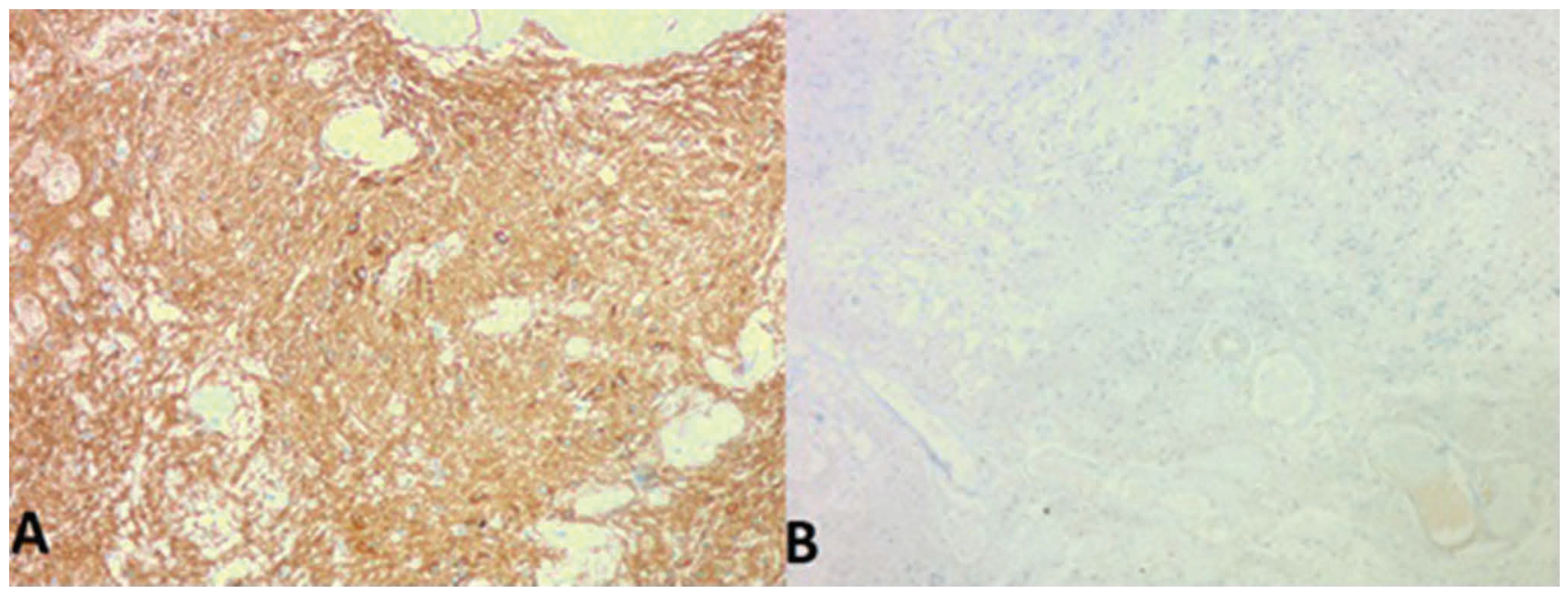

Fig. 4 (A) Glial fibrillary acidic protein (GFAP) shows diffuse positivity on stroma and cells. (B) Epithelial membrane antigen (EMA) shows negative staining on stroma and cells.

of presentation of approximately 44 years with a strong male prevalence. ${ }^{2,4}$ The symptomatic subependymomas generally occur after 40 years of age and are rare in childhood. In contrast to intracranial subependymomas arising in the ventricles, spinal subependymomas cause symptoms because of the limited space in the spinal cord. ${ }^{1,5}$ MRI is sensitive to spinal subependymomas, usually showing a hypointense lesion on the T1-weighted image with gadolinium enhancement, ${ }^{1}$ but it is not capable of distinguishing. ${ }^{1,6}$

There are few descriptions of the cytologic features of subependymoma because this neoplasm is rare and most commonly encountered incidentally at autopsies. 
Histopathologically, these tumors are low grade (World Health Organization [WHO] grade I), ${ }^{2}$ characterized by homogenous cells with sparse cellularity showing clustering of nuclei over a fibrillary background formed by cell processes and occasional occurrence of microcysts, ${ }^{2,5}$ The nuclei are round to slightly oval and resemble those of ependymal cells. There are occasional perivascular arrangements similar to ependymal pseudorosettes.

Immunohistochemical characteristics are, however, identical to that of astrocytic neoplasms with diffuse GFAP and S-100 protein positivity. In contrast to ependymomas, subependymomas are negative for EMA. Ultrastructurally, they demonstrate both astrocytic and ependymal characteristics. The former is evidenced by the processes containing intermediate filaments and the latter by microlumens, cilia, microvilli, and intercellular junctions ${ }^{2}$

Proliferation studies with mouse monoclonal antibody MIB-1 against the $\mathrm{K}_{\mathrm{i}}-67$ antigen that is associated with cell proliferation reconfirmed the slow growth potential of subependymomas. ${ }^{5,7}$

The histogenesis of these tumors has been debated, since the recognition of the tumor in $1945 .{ }^{8}$ Due to their ultrastructural similarities with ependymal cells, they were initially thought to arise from ependymal cells, with reactive astrocytic proliferation. Because immunohistochemical profile favors a glial origin, they were grouped with low-grade glial tumors. Tanycytes were also proposed as source of origin, due to the presence of ultrastructural features of glial as well as ependymal components. However, the presence of round cells rather than spindle-shaped cells differentiates these lesions from tanycytic ependymomas. The identification of cells similar to subependymal glial precursor cells suggested alternate cell of origin. ${ }^{1,6}$ The tumors were then thought to derive from the subependymal cell plate, also known as the residual periventricular matrix layer, because the histologic appearance of the tumor resembled the normal histologic appearance of this region. ${ }^{2,5}$

Electron microscopy of four cases of fourth ventricular subependymomas found cells similar to the ependymal glial precursor cells seen in adult subependymal cell layers, suggesting that subependymomas are a separate entity from ependymomas and astrocytomas, probably arising from ependymal glial cells in the subependymal cell layer. ${ }^{9}$
Subependymal zone glial precursor cell origin cannot explain the predominant peripheral and exophytic location of these lesions in the spinal cord unlike their intracranial counterparts. The current concept seems to suggest that these progenitor cells exist throughout the spinal cord white matter as well as the root entry zones. They are more localized in the outer subpial white matter than the medial zones, especially at the dorsal and ventral spinocerebellar tracts. They tend to proliferate within their template zones and do not possess transzonal migratory ability. The tumor origin from these cells better explains the eccentric, subpial, and exophytic locations of spinal subependymomas.

\section{Conflict of Interest}

None.

\section{References}

1 Salvati M, Raco A, Artico M, Artizzu S, Ciappetta P. Subependymoma of the spinal cord. Case report and review of the literature. Neurosurg Rev 1992;15(1):65-69

2 Krishnan SS, Panigrahi M, Pendyala S, Rao SI, Varma DR. Cervical subependymoma: a rare case report with possible histogenesis. J Neurosci Rural Pract 2012;3(3):366-369

3 Kurukumbi M, Muley A, Ramidi G, Wynn Z, Trouth AJ. A rare case of subependymoma with an atypical presentation: a case report. Case Rep Neurol 2011;3(3):227-232

4 Zenmyo M, Ishido Y, Terahara M, et al. Intramedullary subependymoma of the cervical spinal cord: a case report with immunohistochemical study. Int J Neurosci 2010;120(10):676-679

5 Matsumoto K, Nakagaki $\mathrm{H}$. Intramedullary subependymoma occupying the right half of the thoracic spinal cord-case report. Neurol Med Chir (Tokyo) 2002;42(8):349-353

6 Akutsu H, Shibata Y, Okazaki M, Hyodo A, Matsumura A. Intramedulallary clear cell ependymoma in the cervical spinal. Neurosurgery 2000;47(6):1434-1437

7 Jallo GI, Zagzag D, Epstein F. Intramedullary subependymoma of the spinal cord. Neurosurgery 1996;38(2):251-257

8 Shiboski SC, Shiboski CH, Criswell L, et al; Sjögren's International Collaborative Clinical Alliance (SICCA) Research Groups. American College of Rheumatology classification criteria for Sjögren's syndrome: a data-driven, expert consensus approach in the Sjögren's International Collaborative Clinical Alliance cohort. Arthritis Care Res (Hoboken) 2012;64(4):475-487

9 Moss TH. Observations on the nature of subependymoma: an electron microscopic study. Neuropathol Appl Neurobiol 1984;10(1):63-75 